\title{
Primary Hypothyroidism: Presence of Central Adiposity and Its Improvement on Attaining Euthyroid State with L-Thyroxine
}

\author{
Reshma A. Esmail ${ }^{1}$, Rachael E. Hinrichs ${ }^{2}$, Udaya M. Kabadi ${ }^{1,2,3 *}$ \\ ${ }^{1}$ VA Central Iowa Health Care System, Des Moines, USA \\ ${ }^{2}$ Des Moines University, Des Moines, USA \\ ${ }^{3}$ University of Iowa, Iowa City, USA \\ Email: "ukabadi@gmail.com
}

Received July 15, 2013; revised August 13, 2013; accepted August 19, 2013

Copyright (C) 2013 Reshma A Esmail et al. This is an open access article distributed under the Creative Commons Attribution License, which permits unrestricted use, distribution, and reproduction in any medium, provided the original work is properly cited.

\begin{abstract}
Objective: Primary hypothyroidism is frequently manifested by weight gain. Moreover, treatment with L-Thyroxine reverses the weight gain in most subjects on achieving euthyroid state. However, the characteristic fat distribution contributing to these changes in body weight is not well documented. Therefore, the presence of central adiposity was examined in primary hypothyroidism prior to and after attaining and maintaining euthyroid state following L-Thyroxine therapy. Methods: Waist and hip measurements were conducted to determine waist: hip ratios in 55 men, ages 39 to 84 years at diagnosis of primary hypothyroidism established by subnormal Free T4 and supernormal TSH concentrations and again after their normalization by L-Thyroxine replacement therapy. The subjects were divided according to Body Mass Index (BMI-Kg/m ${ }^{2}$ ) into 3 groups; hypo T1, 20 men with BMI < 25; Hypo T2, BMI 25 - 30 and Hypo T3, BMI > 30. 15 euthyroid normal $(\mathrm{N})$ men matched for age and BMI in each group participated as controls. Results: Mean waist: hip ratio was significantly higher $(\mathrm{p}<0.01)$ in subjects with primary hypothyroidism $(0.97+0.03)$ than in healthy men $(0.92+0.02)$ and declined significantly $(\mathrm{p}<0.01)$ on achieving euthyroidism $(0.93+0.02)$. Moreover, waist: hip ratios were also higher in individual hypothyroid groups; Hypo T1, $0.92+0.01$ vs. N1, $0.88+0.01$; Hypo T2, $0.96+0.02$ vs. $\mathrm{N} 2,0.92+0.02$ and Hypo T3, $1.02+0.03$ vs. N3, $0.98+0.02$ (p < 0.01 for all comparisons). Finally, waist: hip ratios declined significantly in all groups on attaining euthyroidism; Hypo T1, $0.89+0.01$; Hypo T2, $0.93+0.02$; Hypo T3, $0.98+0.02(\mathrm{p}<0.01$ vs. pretreatment). Conclusion: Central adiposity is a definitive clinical manifestation of primary hypothyroidism in men. Moreover, a significant improvement on achieving euthyroid state following L-Thyroxine therapy may deem central adiposity to be a major contributor to changes in body weight in primary hypothyroidism noted at diagnosis and on attaining and maintaining euthyroid state.
\end{abstract}

Keywords: Primary Hypothyroidism; Central Obesity; Body Weight

\section{Introduction}

Primary hypothyroidism frequently presents with non specific clinical manifestations and the diagnosis is established by subnormal serum Free T4 concentration and super normal TSH level. Weight gain is a prominent manifestation of primary hypothyroidism and attaining and maintaining euthyroid state with L-Thyroxine induces a decline in body weight in most subjects [1]. Moreover, clinical hypothyroidism is associated with lipid abnormalities, increased cardiovascular risk and atherosclerosis [2]. Finally, L-Thyroxine treatment in patients with clinical and subclinical hypothyroidism is documented to

${ }^{*}$ Corresponding author. improve dyslipidemia and these outcomes [3]. However, the contributions of various body constituents including total body fat and specifically central fat distribution to these alterations in body weight in primary hypothyroidism prior to and following achieving euthyroid state has not been elucidated. Therefore, we assessed the presence of central obesity in subjects with primary hypothyroidism prior to and after attaining and maintaining euthyroid state as documented by desirable normal free T4 and TSH concentrations with L-Thyroxine therapy.

\section{Subjects and Methods}

55 men, ages 39 - 84 with the diagnosis of primary hypo- 
thyroidism established by subnormal Free $\mathrm{T} 4$ and elevated TSH concentrations participated in the study after obtaining informed consent. The study was approved by institutional review board and the human studies subcommittee at the medical center. Subjects with Diabetes Mellitus were excluded. The subjects were divided into 3 groups according to Body Mass Indices (BMI- $\mathrm{Kg} / \mathrm{M}^{2}$ ). Hypo T1, 20 men with BMI < 25; Hypo T2, BMI 25 - 30; Hypo T3, BMI $>30.15$ euthyroid men matched for age and BMI with normal Free T4 and TSH levels participated as controls in each group.

Waist and hip measurements were performed and waist: hip ratios were calculated in subjects with primary hypothyroidism at diagnosis and again after attainment and maintenance of euthyroid state with L-Thyroxine replacement therapy. Measurements were also conducted for the control subjects. Serum Free T4 and TSH concentrations were determined by local laboratory with wellestablished commercial assay kits. Statistical analyses were conducted by student's " $t$ " test amongst all groups.

\section{Results}

Waist: hip ratios were significantly higher in men with primary hypothyroidism as an entire cohort at diagnosis in comparison to all euthyroid men as a group (Table 1). Moreover, WHRs were also higher in the individual hypothyroid groups in comparison to euthyroid subjects divided according to BMI (Tables 2-4). Finally, WHRs declined in the entire cohort as well as the individual groups following attainment and maintenance of a euthyroid state with L Thyroxine replacement therapy (Tables 1-4).

\section{Discussion}

Many clinical manifestations contribute to metabolic syndrome. These include central obesity, hypertension, dyslipdemia, e.g., hypertriglyceridemia and low levels of high-density lipoprotein (HDL) and hyperglycemia including prediabetes as well as type 2 diabetes induced by insulin resistance [4-8]. A strong association is also well documented between waist circumference on one aspect

Table 1. Free T4, TSH, Body Mass Index (BMI) and Waist: Hip Ratio (WHR) in all Subjects with Hypothyroidism (Hypo T) prior to (Pre Rx) and after (Post Rx) Achieving Euthyroidism with L-Thyroxine Replacement Therapy.

\begin{tabular}{ccccc}
\hline Subjects & Free T4 $\mu \mathrm{g} / \mathrm{dl}$ & $\mathrm{TSH} \mu \mathrm{U} / \mathrm{ml}$ & $\mathrm{BMI} \mathrm{Kg} / \mathrm{M}^{2}$ & WHR \\
\hline Pre RX & $0.54 \pm 0.15^{*}$ & $43 \pm 8^{*}$ & $29.18 \pm 0.72$ & $0.97 \pm 0.03^{*}$ \\
Post Rx & $1.27 \pm 0.21$ & $1.71 \pm 0.19$ & $28.78 \pm 0.59$ & $0.93 \pm 0.02$ \\
& $1.21 \pm 0.21$ & $2.23 \pm 0.24$ & & \\
Normal & $(0.7-1.6)^{\dagger}$ & $(0.4-4.0)^{\dagger}$ & $27.92 \pm 0.54$ & $0.92 \pm 0.02$ \\
\hline
\end{tabular}

${ }^{*} \mathrm{P}<0.01$ vs. Post Rx and Normal, ${ }^{\dagger}$ Normal Range.
Table 2. Free T4, TSH, Body Mass Index (BMI) and Waist: Hip Ratio (WHR) in all Subjects with BMI $<25 \mathrm{Kg} / \mathrm{M}^{2}$ (Hypo T1) prior to (Pre Rx) and after (Post Rx) Achieving Euthyroidism with L-Thyroxine Replacement Therapy.

\begin{tabular}{ccccc}
\hline Subjects & Free $_{4} \mu \mathrm{g} / \mathrm{dl}$ & $\mathrm{TSH} \mu \mathrm{U} / \mathrm{ml}$ & $\mathrm{BMI} \mathrm{Kg} / \mathrm{m}^{2}$ & WHR \\
\hline Pre Rx & $0.56 \pm 0.12^{*}$ & $37 \pm 7^{*}$ & $22.90 \pm 0.39$ & $0.92 \pm 0.01^{*}$ \\
Post Rx & $1.21 \pm 0.60$ & $1.8 \pm 0.2$ & $22.84 \pm 0.37$ & $0.89 \pm 0.01$ \\
& $1.21 \pm 0.21$ & $2.23 \pm 0.24$ & $23.30 \pm 0.38$ & $0.88 \pm 0.01$ \\
Normal & $(0.7-1.6)^{\dagger}$ & $(0.4-4.0)^{\dagger}$ & & \\
\hline
\end{tabular}

${ }^{*} \mathrm{P}<0.01$ vs. Post Rx and Normal, ${ }^{\dagger}$ Normal Range.

Table 3. Free T4, TSH, Body Mass Index (BMI) and Waist: Hip Ratio (WHR) in all Subjects with BMI $25-30 \mathrm{Kg} / \mathrm{M}^{2}$ (Hypo T2) prior to (Pre Rx) and after (Post Rx) Achieving Euthyroidism with L-Thyroxine Replacement Therapy.

\begin{tabular}{ccccc}
\hline Subjects & Free T4 $\mu \mathrm{g} / \mathrm{dl}$ & $\mathrm{TSH} \mu \mathrm{U} / \mathrm{ml}$ & $\mathrm{BMI} \mathrm{Kg} / \mathrm{M}^{2}$ & WHR \\
\hline Pre Rx & $0.48 \pm 0.11^{*}$ & $47 \pm 9^{*}$ & $27.68 \pm 0.44$ & $0.96 \pm 0.01^{*}$ \\
Post Rx & $1.18 \pm 0.18$ & $1.68 \pm 0.19$ & $26.82 \pm 0.41$ & $0.93 \pm 0.02$ \\
& $1.21 \pm 0.21$ & $2.23 \pm 0.24$ & & \\
Normal & $(0.7-1.6)^{\dagger}$ & $(0.4-4.0)^{\dagger}$ & $27.12 \pm 0.43$ & $0.92 \pm 0.02$ \\
\hline
\end{tabular}

${ }^{*} \mathrm{P}<0.01$ vs. Post Rx and Normal, ${ }^{\dagger}$ Normal Range.

Table 4. Free T4, TSH, Body Mass Index (BMI) and Waist: Hip Ratio (WHR) in all Subjects with BMI $>30 \mathrm{Kg} / \mathrm{M}^{2}$ (Hypo T3) prior to (Pre Rx) and after (Post Rx) Achieving Euthyroidism with L-Thyroxine Replacement Therapy.

\begin{tabular}{ccccc}
\hline Subjects & Free T4 $\mu \mathrm{g} / \mathrm{dl}$ & $\mathrm{TSH} \mu \mathrm{U} / \mathrm{ml}$ & $\mathrm{BMI} \mathrm{Kg} / \mathrm{M}^{2}$ & WHR \\
\hline Pre RX & $0.52 \pm 0.14^{*}$ & $43 \pm 7^{*}$ & $34.28 \pm 1.15$ & $1.02 \pm 0.03^{*}$ \\
Post Rx & $1.27 \pm 0.21$ & $1.71 \pm 0.19$ & $34.18 \pm 0.96$ & $0.98 \pm 0.02$ \\
& $1.21 \pm 0.21$ & $2.23 \pm 0.24$ & & \\
Normal & $(0.7-1.6)^{\dagger}$ & $(0.4-4.0)^{\dagger}$ & $34.12 \pm 0.84$ & $0.98 \pm 0.02$ \\
\hline
\end{tabular}

${ }^{*} \mathrm{P}<0.01$ vs. Post Rx and Normal, ${ }^{\dagger}$ Normal Range.

and atherosclerotic risk factors as well as cardiovascular morbidity and mortality as well as all cause mortality [5,9-12]. Furthermore, increased intra-abdominal fat as assessed by computer tomography is independently associated with each of the five components of metabolic syndrome; hypertension, waist circumference, HDL cholesterol, triglycerides and fasting plasma glucose [5-7, $9,12]$. Therefore, central or visceral obesity is deemed a major required component for the clinical diagnosis of metabolic syndrome by the International Diabetes Federation as well as many other organizations in USA including National Institutes of Health [7,13-15]. Moreover, central obesity has also been shown to precede onset of other manifestations of metabolic syndrome [16]. Finally, reduction in waist circumference improves manifestations of metabolic syndrome and therefore its adverse outcomes [16]. However, waist: hip ratio is apparently a better index of central obesity since normal measure- 
ments of $\leq 0.84$ for women and $\leq 0.90$ for men are universal whereas normal waist circumference measurements vary according ethnic groups e.g. smaller in south east Asians as compared to Western Population $[8,10$, $14,15]$.

This study demonstrates that waist: hip ratio is raised in men with primary hypothyroidism with a significant improvement on achieving euthyroid state irrespective of initial body weight or its change following L-Thyroxine replacement therapy. This finding is consistent although sparsely described in the literature [17-21]. Moreover, it is noteworthy that the decline in waist: hip ratio occurred despite lack of a significant weight loss as expressed by BMI in men with primary hypothyroidism in this study, a finding consistent with previous observation [22]. However, the lack of significant weight loss noted in this study in contrast to another study may be attributed to the major difference between the severity of hypothyroidism in participating subjects as documented by pretreatment mean serum TSH concentrations, $43 \mu \mathrm{U} / \mathrm{ml}$ in our subjects in comparison to $102 \mu \mathrm{U} / \mathrm{ml}$ in the other study [23].

Waist: hip ratio is well documented to be a reliably index of central obesity and central obesity has been shown to precede onset of other manifestations of metabolic syndrome [8,10-16]. Therefore, the presence of other manifestations of metabolic syndrome especially dyslipidemia in subjects with primary hypothyroidism may be attributed to central obesity as documented in several previous studies [2,13-15]. Moreover, a decrease in central obesity as expressed by a decline in waist: hip ratio on attaining and maintaining euthyroid state with LThyroxine replacement therapy may be a major contributor in inducing improvement in dyslipidemia and other manifestations of metabolic syndrome in primary hypothyroidism documented previously [2,24].

The major limitation of this study is the participants who were exclusively men because of the study site being a Veterans Affairs Medical Center and the vast majority of patients receiving care at the facility are men. However, the clinical manifestations of primary hypothyroidism including changes in body weight are similar in men and women, the lone exception being the specific symptoms and signs pertaining to derangement involving reproductive system. Thus, the data noted in men in this study may be applicable to women as well though requiring documentation in a larger cohort.

Therefore, central obesity as expressed by a reliable index, waist: hip ratio may be a characteristic manifestation of primary hypothyroidism in men with a decline to normalization on achieving and maintaining euthyroid state following L-Thyroxine replacement therapy.

\section{REFERENCES}

[1] J. Pears, R. T. Jung and A. Gunn, "Long-Term Weight
Changes in Treated Hyperthyroid and Hypothyroid Patients," Scottish Medical Journal, Vol. 35, No. 6, 1990, pp. 180-182.

[2] W. M. Kong, M. H. Sheikh, P. J. Lumb, et al., "A 6Month Randomized Trial of Thyroxine Treatment in Women with Mild Subclinical Hypothyroidism," American Journal of Medicine, Vol. 112, No. 5, 2002, pp. 348-354. doi:10.1016/S0002-9343(02)01022-7

[3] C. S. Fox, M. J. Pencina, R. B. D'Agostino, et al., "Relations of Thyroid Function to Body Weight: Cross-Sectional and Longitudinal Observations in a CommunityBased Sample," Archives of Internal Medicine Vol. 168, No. 6, 2008 pp. 587-592.

doi:10.1001/archinte.168.6.587

[4] S. M. Haffner, M. P. Stern, H. P. Hazuda, et al., "Do Upper-Body and Centralized Adiposity Measure Different Aspects of Regional Body-Fat Distribution? Relationship to Non-Insulin-Dependent Diabetes Mellitus, Lipids, and Lipoproteins," Diabetes, 1987. Vol. 36, No. 1, pp. 43-51. doi:10.2337/diabetes.36.1.43

[5] L. van Gaal, E. Rillaerts, W. Creten, et al., "Relationship of Body Fat Distribution Pattern to Atherogenic Risk Factors in NIDDM. Preliminary Results," Diabetes Care, Vol. 11, No. 2, 1988, pp. 103-106. doi:10.2337/diacare.11.2.103

[6] K. M. Utzschneider, D. B. Carr, R. L. Hull, et al., "Impact of Intra-Abdominal Fat and Age on Insulin Sensitivity and Beta-Cell Function," Diabetes, Vol. 53, No. 11, 2004, pp. 2867-2872. doi:10.2337/diabetes.53.11.2867

[7] D. B. Carr, K. M. Utzschneider, R. L. Hull, et al., "IntraAbdominal Fat Is a Major Determinant of the National Cholesterol Education Program Adult Treatment Panel III Criteria for the Metabolic Syndrome," Diabetes, Vol. 53, No. 8, pp. 2087-2094. doi:10.2337/diabetes.53.8.2087

[8] A. Madhavan, R. Beena Kumari and M. G. Sanal, "A Pilot Study on the Usefulness of Body Mass Index and Waist Hip Ratio as a Predictive Tool for Gestational Diabetes in Asian Indians," Gynecological Endocrinology, Vol. 24, No. 12, 2008, pp. 701-707. doi:10.1080/09513590802444134

[9] E. Lapice, S. Maione, L. Patti, et al., "People," Diabetes Care, Vol. 32, No. 9, 2009, pp. 1734-1736. doi:10.2337/dc09-0176

[10] L. de Koning, A. T. Merchant, J. Pogue, et al., "Waist Circumference and Waist-to-Hip Ratio as Predictors of Cardiovascular Events: Meta-Regression Analysis of Prospective Studies," European Heart Journal, Vol. 28, No. 7, 2007, pp. 850-856. doi:10.1093/eurheartj/ehm026

[11] J. S. Ho, J. J. Cannaday, C. E. Barlow, et al., "Comparative Relation of General, Central, and Visceral Adiposity Measures for Coronary Artery Calcium in Subjects without Previous Coronary Events," American Journal of Cardiology, Vol. 104, No. 7, 2009, pp. 943-946. doi:10.1016/j.amjcard.2009.05.047

[12] T. Coutinho, K. Goel, D. de sá Corrêa, et al., "Combining Body Mass Index with Measures of Central Obesity in the Assessment of Mortality in Subjects with Coronary Disease: Role of 'Normal Weight Central Obesity'," Journal of the American College of Cardiology, Vol. 61, No. 5, 
2013, pp. 553-556 doi:10.1016/j.jacc.2012.10.035

[13] S. Grundy, H. Brewer Jr., J. Cleeman, et al., "Definition of Metabolic Syndrome. Report of the National Heart, Lung, and Blood Institute/American Heart Association Conference on Scientific Issues Related to Definition," Circulation, Vol. 3, 2004, pp. 433-438.

[14] P. Segal and P. Zimmet, "Treatment of the Metabolic Syndrome," The 1st International Congress on Prediabetes and the Metabolic Syndrome, Berlin, 13-16 April 2005.

[15] E. Kassi, P. Pervanidou, P. Kaltsas, et al., "Metabolic Syndrome: Definitions and Controversies," BMC Medicine, Vol. 9, 2011, pp. 48-55. doi:10.1186/1741-7015-9-48

[16] A. J. Cameron, E. J. Boyko, R. A. Sicree, et al., "Central Obesity as a Precursor to the Metabolic Syndrome in the AusDiab Study and Mauritius," Obesity, Vol. 16, No. 12, 2008, pp. 2707-2716. doi:10.1038/oby.2008.412

[17] G. P. Shantha, A. A. Kumar, V. Jeyachandran, et al., "Association between Primary Hypothyroidism and Metabolic Syndrome and the Role of C Reactive Protein: A Cross-Sectional Study from South India," Thyroid Research, Vol. 2, No. 1, 2009, p. 2. doi:10.1186/1756-6614-2-2

[18] C. Liu, W. A. Scherbaum, M. Schott and S. Schinner, "Subclinical Hypothyroidism and the Prevalence of the Metabolic Syndrome," Hormone and Metabolic Research, Vol. 43, No. 6, 2011, pp. 417-421. doi:10.1055/s-0031-1275719

[19] M. Erdogan, A. Canataroglu, S. Ganidagli, et al., "Meta- bolic Syndrome Prevalence in Subclinic and Overt Hypothyroid Patients and the Relation among Metabolic Syndrome Parameters," Journal of Endocrinological Investigation, Vol. 34, No. 7, 2011, pp. 488-492.

[20] A. O. Ogbera, S. Kuku and O. Dada, "The Metabolic Syndrome in Thyroid Disease: A Report from Nigeria," Indian Journal of Endocrinology and Metabolism, Vol. 16, No. 3, 2012, pp. 417-422. doi: $10.4103 / 2230-8210.95688$

[21] A. C. Waring, N. Rodondi, S. Harrison, et al., "Health, Ageing, and Body Composition (Health ABC) Study. Thyroid Function and Prevalent and Incident Metabolic Syndrome in Older Adults: The Health, Ageing and Body Composition Study," Clinical Endocrinology (Oxford), Vol. 76, No. 6, 2012, pp. 911-918. doi:10.1111/j.1365-2265.2011.04328.x

[22] B. J. Hoogwerf and F. Q. Nuttall, "Long-Term Weight Regulation in Treated Hyperthyroid and Hypothyroid Subjects," Am J Med. Vol. 76, No. 6, 1984, pp. 963-970. doi:10.1016/0002-9343(84)90842-8

[23] J. Karmisholt, S. Andersen and P. Laurberg, "Weight Loss after Therapy of Hypothyroidism Is Mainly Caused by Excretion of Excess Body Water Associated with Myxoedema," The Journal of Clinical Endocrinology \& Metabolism, Vol. 96, No. 1, 2011, pp. E99-E103. doi:10.1210/jc.2010-1521

[24] I. Kowalska, J. Borawski, A. Nikołajuk, et al., "Insulin Sensitivity, Plasma Adiponectin and sICAM-1 Concentrations in Patients with Subclinical Hypothyroidism: Response to Levothyroxine Therapy," Endocrine, Vol. 40, No. 1, 2011, pp. 95-101. doi:10.1007/s12020-011-9446-5

\section{Abbreviations}

T4-Thyroxine; TSH—Thyroid Stimulating Hormone; Hypo T-Hypothyroidism; WHR — Waist: Hip Ratio; BMI—Body Mass Index; N—Normal. 